Artikel

\title{
PENERAPAN ASSOCIATION RULE DATA MINING UNTUK REKOMENDASI PRODUK KOSMETIK PADA PT. FABIANDO SEJAHTERA MENGGUNAKAN ALGORITMA APRIORI
}

\author{
Febriantho $^{1}$, Dram Renaldi $^{2}$, Yakub $^{3}, E d y^{4}$ \\ 1, 2, 3,4 Universitas Buddhi Dharma, Teknik Informatika, Banten, Indonesia
}

\begin{tabular}{l}
\hline SUBMISSION TRACK \\
\hline Recieved: August 20, 2020 \\
Final Revision:August 8, 2020 \\
Available Online: \\
KATA KUNCI \\
\hline DataMining, Association Rule, Apriori, \\
Kosmetik \\
KORESPONDENSI \\
\hline Phone: 089628492422 \\
E-mail: febricipuy@ gmail.com
\end{tabular}

\section{PENGANTAR}

Pada beberapa perusahaan yang memliki data transaksi penjualan dan data tersebut akan bertambah banyak dari hari ke hari sehingga akan menumpuk dan menjadi sampah jika tidak dikelola dan dimanfaatkan dengan baik. Data transaksi penjualan adalah salah satu hal yang dapat dimanfaatkan untuk

\begin{abstract}
A B S T R A K
Pada beberapa perusahaan yang memliki data transaksi penjualan dan data tersebut akan bertambah banyak dari hari ke hari sehingga akan menumpuk dan menjadi sampah jika tidak di kelola dan di manfaatkan dengan baik. Data transaksi penjualan adalah salah satu hal yang dapat dimanfaatkan untuk meningkatkan penjualan produk. Tidak hanya untuk meningkatkan penjualan produk namun juga dapat memberikan rekomendasi produk untuk setiap penjualannya. Seperti di bagian pengaturan stock produk dapat memberikan rekomendasi jumlah produk agar tidak terjadinya masalah seperti over stock yang akan menyebabkan jumlah dalam suatu produk menjadi kadaluarsa. Pada penelitian ini, akan di lakukan penerapan association rule data mining untuk rekomendasi produk kosmetik menggunakan algoritma Apriori Pengujian hasil penggunaan data mining dan algoritma Apriori dilakukan untuk mengetahui bahwa hasil dari penelitian dapat menemukan association rules dari dataset yang ada untuk merekomendasikan produk kosmetik. Metode association rule digunakan dalam pencarian pola keterikatan produk untuk strategi penjualan dalam kebijakan pengambilan keputusan. Sehingga dapat diketahui kosmetik yang sering dibeli oleh konsumen, berdasarkan rule-rule yang dihasilkan dari data-data yang terdapat di dalam database. Pengujian dilakukan dengan menggunakan aplikasi rapidminer 9.5. Hasil yang didapat dari pengujian tersebut adalah didapatkan 16 aturan (rule) yang akan di gunakan untuk pengambilan keputusan dalam rekomendasi produk kosmetik.
\end{abstract}

meningkatkan penjualan produk. Tidak hanya untuk meningkatkan penjualan produk namun juga dapat memberikan rekomendasi produk untuk setiap penjualannya. Seperti di bagian pengaturan stock produk dapat memberikan rekomendasi jumlah produk agar tidak terjadinya masalah seperti over stock (persediaan berlebih) yang akan menyebabkan jumlah dalam suatu produk 
menjadi kadaluarsa (tidak laku). Pengujian yang dapat di terapkan dalam permasalahan ini adalah dengan menerapkan penggunaan data mining dan algoritma Apriori. Data mining adalah sebuah proses menggali suatu data untuk mendapakan berbagai informasi yang berguna dan dapat di gunakan untuk bahan pengambilan keputusan rekomendasi produk. Salah satu cara penerapan dalam data mining tersebut adalah dengan cara menggunakan fungsi algoritma Apriori sebagai metodenya. Apriori adalah salah satu metode data mining yang digunakan untuk mengetahui item-item yang sering dibeli secara bersamaan oleh konsumen. Association rule yang dimaksud dilakukan melalui mekanisme penghitungan support dan confidence dari suatu hubungan item. Sebuah rule asosiasi dikatakan interesting jika nilai support adalah lebih besar dari minimum 2 support dan juga nilai confidence adalah lebih besar dari minimum confidence. Algoritma Apriori ini akan cocok untuk diterapkan bila terdapat beberapa hubungan item yang ingin dianalisa. Salah satunya yang bisa diterapkan adalah di dalam bidang usaha dalam rekomendasi produk kosmetik. Ada berbagai pengujian yang menerapkan algoritma yang sama, hanya saja penggunaannya untuk halhal yang berbeda seperti pada analisa pola belanja konsumen pada toko buku, pola pembelian konsumen sparepart motor dan ada juga untuk rekomendasi penjualan buahbuahan, peneliti ini tidak jauh berbeda dalam kasus kasus pengujian yang sebelumnya, hanya saja objeknya yang berbeda yaitu berfokus pada objek penjualan produk kosmetik. Dengan semakin banyak data yang ada pada pengujian ini, maka akan semakin meningkatkan jumlah presentase yang akan di hasilkan. Website atau yang biasa di sebut web adalah halaman informasi yang disediakan melalui jalur internet sehingga dapat diakses di seluruh dunia selama terkoneksi dengan jaringan internet. website merupakan kumpulan halaman yang menampilkan informasi data teks, data gambar diam atau gerak, data animasi, suara, video dan atau gabungan dari semuanya, baik yang bersifat statis maupun dinamis yang membentuk satu rangkaian bangunan yang saling terkait dimana masing-masing dihubungkan dengan jaringan-jaringan halaman (hyperlink). Berdasarkan latar belakang yang telah di jelaskan maka di usulkan "Penerapan Association Rule Data Mining untuk Rekomendasi Produk Kosmetik pada PT. Fabindo Sejahtera menggunakan Algoritma Apriori" dengan harapan dapat membantu PT. Fabindo Sejahtera dalam memberikan informasi produk yang layak untuk di rekomendasikan berdasarkan association rule yang ada.

\section{METODE}

\subsection{Algoritma Apriori}

[1] Algoritma Apriori termasuk jenis aturan asosiasi pada data mining. [2] Apriori adalah salah satu pendekatan yang sering digunakan pada frequent itemset mining. Prinsip Apriori adalah jika sebuah itemset infrequent, maka itemset yang infrequent tidak perlu lagi di explore superset nya sehingga jumlah kandidat yang harus diperiksa menjadi berkurang. Apriori adalah Algoritma untuk frequent itemset mining dan association rule dalam database transaksional. Di hasilkan dengan menidentifikasi setiap buah item, dan memperluasnya menjadi kombinasi kumpulan item yang lebih besar asalkan himpunan item muncul cukup sering dalam database. [3] Apriori adalah salah satu algoritma dalam data mining yang paling terkenal dalam menemukan pola data atau pola kemunculan/frekuensi data. Biasa algoritma Apriori digunakan untuk menemukan pola pembelian pelanggan pada suatu minimarket berdasarkan transaksi pembelian. Dalam algoritma Apriori adalah istilah nilai support yaitu nilai yang digunakan untuk mengukur kemunculan data tertentu dibandingkan dengan total data. [4] Algoritma Apriori adalah salah satu algoritma yang melakukan pencarian frequent itemset dengan menggunakan teknik association rule. Untuk mencari association 
rule dari suatu kumpulan data, tahap pertama yang harus dilakukan adalah mencari frequent itemset terlebih dahulu. Frequent itemset adalah sekumpulan item yang sering muncul secara bersamaan. Penting tidaknya suatu asosiasi dapat diketahui dengan dua tolak ukur, yaitu support dan confidence. Support adalah nilai penunjang atau persentase kombinasi sebuah item dalam database, sedangkan confidence adalah nilai kepastian yaitu kuatnya hubungan antar item dalam aturan asosiasi. Proses utama yang dilakukan dalam algoritma Apriori untuk mendapat frequent itemset yaitu:

\section{Join (penggabungan).}

Proses ini dilakukan dengan cara pengkombinasian item dengan yang item lainya hingga tidak bisa terbentuk kombinasi lagi.

2. Prune (pemangkasan).

Proses pemangkasan yaitu hasil dari item yang telah dikombinasikan kemudian dipangkas dengan menggunakan minimum support yang telah ditentukan.

\subsection{Association Rules}

Association rules mining Metodologi Association Rules, atau Analisis Asosiasi adalah sebuah metodologi untuk mencari relasi (asosiasi) istimewa/menarik yang tersembunyi dalam himpunan data (atau dataset) yang besar. Salah satu penerapan Metode Association Rules adalah pada Market Basket Analysis. Association rule adalah sebuah ekspresi implikasi dari bentuk $\mathrm{X} \rightarrow \mathrm{Y}$, dimana $\mathrm{X}$ dan $\mathrm{Y}$ adalah itemset yang saling terpisah (disjoint), dengan kata lain $\mathrm{X}$ $\mathrm{n} \mathrm{Y}=\varnothing$. Dalam menentukan association rule, terdapat suatu interestingness measure (ukuran ketertarikan) yang di dapatkan dari hasil pengolahan data dengan perhitungan tertentu. [5] Association rule adalah salah satu metode pada machine learning atau data mining yang digunakan untuk menentukan relasi atau keterkaitan antara satu item dengan item yang lain pada sebuah database. Fungsi pada association rules sering disebut sebagai Market Basket analysis yang bertujuan untuk menemukan korelasi antara himpunan dalam item-item tertentu. Association rule ini juga dapat diterapkan pada database dengan dimensi yang cukup besar yang terdiri atas data transaksi.

Association rule memiliki 2 tahap metode yaitu :

1. Analisa pola frekuensi tinggi

Pada tahapan ini bertujuan untuk mencari kombinasi item yang memenuhi syarat minimum dari nilai support dalam database. Rumus mencari nilai support sebuah item sebagai berikut:

\section{Support $(\mathrm{A})=$}

Jumlah Transaksi mengandung A

Total Transaksi

Sedangkan nilai support dari 2 item di peroleh dari rumus berikut :

Support $(\mathrm{A} n \mathrm{~B})=$

Jumlah Transaksi mengandung A dan B

Total Transaksi

\section{Pembentukan aturan assosiatif}

Setelah menemukan semua pola frekuensi tinggi, tahapan selanjutnya adalah mencari aturan-aturan assosiatif yang memenuhi syarat minimum untuk confidence dengan cara menghitung confidence aturan assosiatif $\mathrm{A} \Omega \mathrm{B}$.

Nilai confidence dari aturan A $\Omega$ B diperoleh dari rumus berikut:

\section{Confidence $=\mathrm{P}(\mathrm{B} \mid \mathrm{A})=$}

Jumlah Transaksi mengandung A dan B

Jumlah Transaksi mengandung A 


\subsection{CRISP-DM (cross-industry standard process for data mining)}

CRISP-DM (cross-industry standard process for data mining) merupakan suatu konsorsium perusahaan yang didirikan oleh Komisi Eropa pada tahun 199616 dan telah ditetapkan sebagai proses standar dalam data mining yang dapat diaplikasikan di berbagai sektor industri.

Berikut ini adalah enam tahap siklus hidup pengembangan data mining :

\section{Business Understanding}

Tahap pertama adalah memahami tujuan dan kebutuhan dari sudut pandang bisnis, kemudian menterjemahkan pengetahuan ini ke dalam pendefinisian masalah pada data mining. Selanjutnya akan ditentukan rencana dan strategi untuk mencapai tujuan tersebut.

\section{Data Understanding}

Tahap ini dimulai dengan pengumpulan data yang kemudian akan dilanjutkan dengan proses untuk mendapatkan pemahaman yang mendalam tentang data, mengidentifikasi masalah kualitas data, atau untuk mendeteksi adanya bagian yang menarik dari data yang dapat digunakan untuk hipotesa untuk informasi yang tersembunyi.

\section{Data Preparation}

Tahap ini meliputi semua kegiatan untuk membangun dataset akhir (data yang akan diproses pada tahap pemodelan) dari data mentah. Tahap ini dapat diulang beberapa kali. Pada tahap ini juga mencakup pemilihan tabel, record, dan atribut-atribut data, termasuk proses pembersihan dan transformasi data untuk kemudian dijadikan masukan dalam tahap pemodelan.

\section{Modelling}

Dalam tahap ini akan dilakukan pemilihan dan penerapan berbagai teknik pemodelan dan beberapa parameternya akan disesuaikan untuk mendapatkan nilai yang optimal. Secara khusus, ada beberapa teknik berbeda yang dapat diterapkan untuk masalah data mining yang sama. Di pihak lain ada teknik pemodelan yang membutuhan format data khusus. Sehingga pada tahap ini masih memungkinan kembali ke tahap sebelumnya.

\section{Evaluation}

Pada tahap ini, model sudah terbentuk dan diharapkan memiliki kualitas baik jika dilihat dari sudut pandang analisa data. Pada tahap ini akan dilakukan evaluasi terhadap keefektifan dan kualitas model sebelum digunakan dan menentukan apakah model dapat mencapat tujuan yang ditetapkan pada fase awal (Business Understanding). Kunci dari tahap ini adalah menentukan apakah ada masalah bisnis yang belum dipertimbangkan. Di akhir dari tahap ini harus ditentukan penggunaan hasil proses data mining.

\section{Deployment}

Pada tahap ini, pengetahuan atau informasi yang telah diperoleh akan diatur dan dipresentasikan dalam bentuk khusus sehingga dapat digunakan oleh pengguna. Tahap deployment dapat berupa pembuatan laporan sederhana atau mengimplementasi kan proses data mining yang berulang dalam perusahaan. Pada banyak kasus, tahap deployment melibatkan konsumen, di samp ing analis data, karena sangat penting bagi konsumen untuk memahami tindakan apa yang harus dilakukan untuk menggunakan model yang telah dibuat.

\section{PERANCANGAN}

\subsection{Business Understanding}

Dalam tahap ini adalah memahami masalah tujuan dan kebutuhan dari sudut pandang bisnis, dibutuhkan pemahaman dari kegiatan data mining yang akan dilakukan. Dalam hal ini adalah identifikasi masalah yang terdapat pada PT. Fabindo Sejahtera ini adalah banyaknya produk-produk kosmetik yang belum terorganisir antara yang banyak terjual dan saling berhubungan dan tidak 
seimbangnya stock barang antara barang yang laku terjual dengan barang yang saling berhubungan sehingga perputaran stock barang tidak terkontrol

\subsection{Data Understanding}

Dalam tahap ini adalah melakukan pengumpulan data awal yang akan digunakan atau diolah nantinya. Data yang akan digunakan adalah data transaksi penjualan produk yang tersimpan di dalam database yang terjadi dalam kurung waktu 1 bulan operasional PT. Fabindo Sejahtera (2 Januari 2020 - 31 Januari 2020). Data inilah yang akan digunakan untuk analisa association rules. Data transaksi diperoleh dari IT Supervisor PT. Fabindo Sejahtera dan data transaksi yang digunakan adalah data primer. Data real transaksi terdiri dari banyaknya jenis kosmetik di PT. Fabindo Sejahtera, Jumlah kosmetik yang ada di PT. Fabindo Sejahtera kurang lebih sebanyak 456 jenis kosmetik. Dalam tahapan ini juga untuk mencoba mengidentifikasi masalahmasalah yang berkaitan dengan kualitas suatu data

\subsection{Data Preparation}

Dari pemahaman akan data pada fase data understanding selanjutnya data-data yang telah terkumpul, menggunakan data transaksi yang sudah didapat kedalam bentuk file excel agar memudahkan dalam pengolahan data, dengan menghilangkan beberapa atribut yang tidak dipakai. Dari banyaknya jenis kosmetik yang terdapat di PT. Fabindo Sejahtera, data yang diambil disini hanya menggunakan 25 jenis kosmetik pada saat melakukan survey, lalu menggunakan data dari transaksi penjualan kosmetik di PT. Fabindo Sejahtera dalam kurung waktu 1 bulan operasional yaitu dimulai dari 2 Januari 2020 sampai dengan 31 Januari 2020 dengan jumlah data transaksi sebanyak 50 transaksi penjualan. Dari data awal berupa data transaksi pembelian konsumen sampai pada membangun dataset, dari dataset ini yang akan diterapkan ke dalam alat permodelan, selanjutnya akan melakukan proses data mining. Pada tahap ini dilakukan beberapa tahapan sehingga menghasilkan data yang dapat digunakan pada prosesnya, sebagai berikut :

\section{Data Cleaning}

Data Cleaning dimaksudkan untuk mengisi missing value atau nilai yang kosong pada field-field akibat dari integrasi data.

\section{Data Transformation}

Pada tahap ini data yang sudah melalui tahap data cleaning selanjutnya akan memulai proses transformasi agar data yang dihasilkan berkualitas.

\section{Data Reduction}

Tahap ini adalah proses preduksian dimensi data, menghilangkan field-field yang dianggap tidak berkontribusi terhadap hasil akhir.

\subsection{Fase Modeling}

Fase modeling merupakan tahapan metode dalam proses data mining yang diterapkan pada data PT. Fabindo Sejahtera. Pemodelan ini dilakukan dengan menggunakan metode Apriori. Metode ini memiliki dua tahapan pengerjaan yaitu:

\section{Mencari nilai support dan confidence}

\section{Menghasilkan association rule}

Dalam tahap pencarian nilai support dan confidence algoritma yang akan digunakan adalah Apriori. Algoritma ini memiliki dasar pengetahuan mengenai nilai support dan confidence yang telah diketahui sebelumnya untuk memproses informasi lebih lanjut. Namun sebelum masuk pada tahapan untuk mempermudah pembentukan nilai support dan confidence akan dilakukan pengkodean terhadap produk yang terdapat produk yang terhadap pada data yang sudah siap digunakan untuk proses mining, proses pengkodean ini berdasarkan nomor setiap produk yang terdapat pada transaksi. 


\subsection{Fase Evaluation}

Pada Tahap ini dataset yang sudah disiapkan kemudian akan diolah menggunakan aplikasi rapidminer 9.5. Tahap ini dimulai menyiapkan data sampel yang sudah ditentukan untuk diolah dan dianalisis. Evaluasi disini akan dilakukan secara mendalam dengan tujuan untuk menyesuaikan hasil pada tahap modeling agar sesuai dengan sasaran yang ingin dicapai dalam tahap Business Understanding.

\subsection{Fase Deployment}

Fase Deployment merupakan tahapan membuat laporan hasil kegiatan data mining. Laporan akhir mengenai pengetahuan yang didapat atau pengenalan pola pada data dalam proses data mining dan dipresentasikan dalam bentuk grafik atau deskripsi yang mudah dipahami. Dan berikut pengetahuan atau hasil dari proses data mining menggunakan rapidminer 9.5 :

Association Rules

1. [RIVERA BOLD INTENSE WATERPRO OF LIQUID LINER] --> [FANBO PRECI OUS WHITE MOISTURIZER] (confidence: $0.625)$.

2. [RIVERA BOLD INTENSE WATERPRO OF LIQUID LINER] --> [FANBO PRECIO US WHITE MILK CLEANSER] (confidenc $e$ : 0.625).

3. [RIVERA MATTE CURSE WATERPRO OF LIQUID LINER] --> [FANBO PRECIO US WHITE MILK CLEANSER] (confidenc $e: 0.625)$.

4. [FANBO PRECIOUS WHITE BB CREA M LIGHT] --> [FANBO ACNE SOLUTION FACIAL FOAM] (confidence: 0.632).

5. [RIV.SHINNING EYE SHADOW NO. 05 MYSTERIOUS MAROON] --> [FANBO PRECIOUS WHITE BB CREAM BEIGE] (confidence: 0.632).
6. [RIV. ENDLESS BRIGHT MULTI ACTI ON NIGHT CREAM] --> [FANBO ACNE S OLUTION FACIAL FOAM] (confidence: 0.636).

7. [FANBO FANTASTIC MOISTURIZER] --> [RIV.SHINNING BLUSH ON 02 BLUSHING ROSES] (confidence: 0.636).

8. [RIV. ENDLESS BRIGHT MULTI ACT ION NIGHT CREAM] --> [FANBO PR ECIOUS WHITE MOISTURIZER] (conf idence: 0.636).

9. [FANBO POWDER PUFF NEW DESIG N 2 PCS] --> [RIV.SHINNING BLUSH ON 02 BLUSHING ROSES] (confidence: $0.650)$.

10. [RIVERA LIPSTICK MATTE NO 204 LAVISH MAUVE] --> [RIVERA MATTE CURSE WATERPROOF LIQUID LINER] (confidence: 0.650).

11. [FANBO BODY SCRUB WITH RICH MILK ESSENCE] --> [FANBO ACNE SOLUTION FACIAL FOAM] (confidence: $0.684)$.

12. [RIV.SHINNING EYE SHADOW NO. 05 MYSTERIOUS MAROON] --> [FANBO PRECIOUS WHITE MILK CLEANSER] (confidence: 0.684).

13. [FANBO ACNE SOLUTION GEL] --> [FANBO ACNE SOLUTION FACIAL FOAM] (confidence: 0.714).

14. [FANBO FANTASTIC MASKARA WO NDERFULL 8 ML] --> [FANBO PRE CIOUS WHITE PERFECT LASH MAS CARA] (confidence: 0.722).

15. [FANBO BODY SCRUB WITH SAKU RA EXTRACT] --> [RIV.SHINNING BLUSH ON 02 BLUSHING ROSES] (confidence: 0.800 ). 
16. [RIVERA MATTECURSE WATERPR OOF LIQUID LINER] --> [RIVERA LIPSTICK MATTE NO 204 LAVISH MAUVE] (confidence: 0.812).

\section{III.PEMBAHASAN}

\subsection{Tampilan Program}

a. Halaman Login

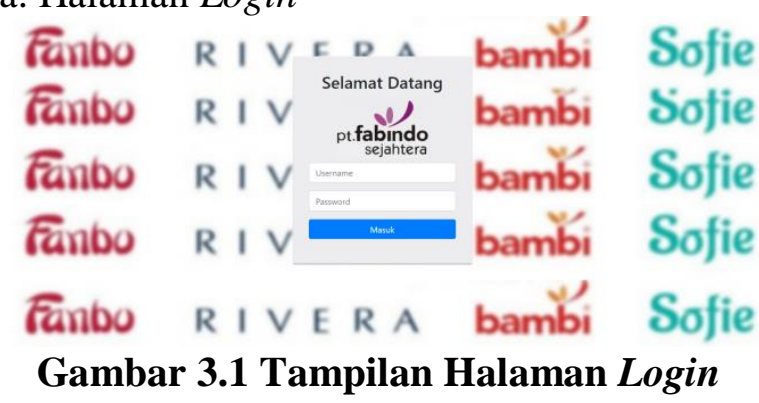

b. Halaman Utama

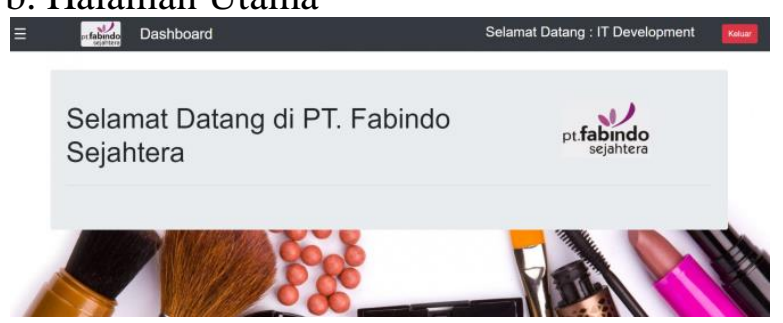

Gambar 3.2 Tampilan Halaman Utama

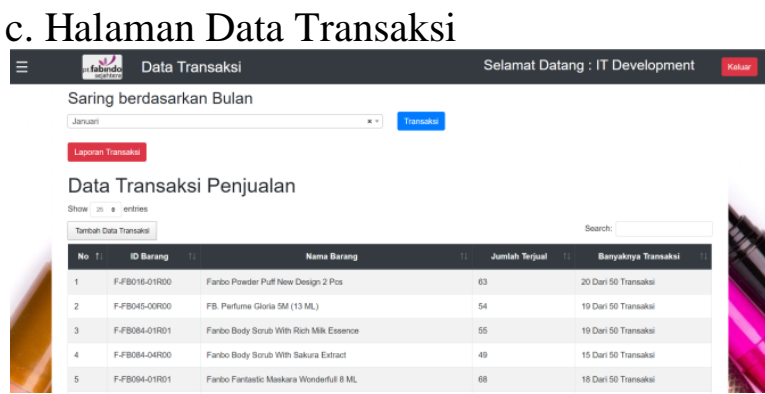

Gambar 3.3 Tampilan Halaman Data Transaksi

d. Halaman Rekomendasi Barang

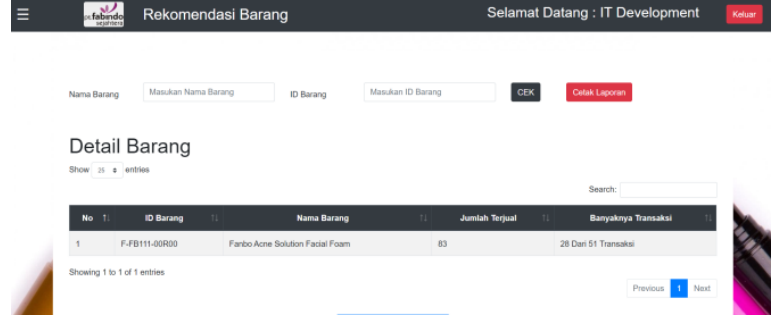

Gambar 3.4 Tampilan Halaman Rekomendasi Barang

e. Halaman Hasil Rekomendasi Barang Semua Rekomendasi 2 Barang

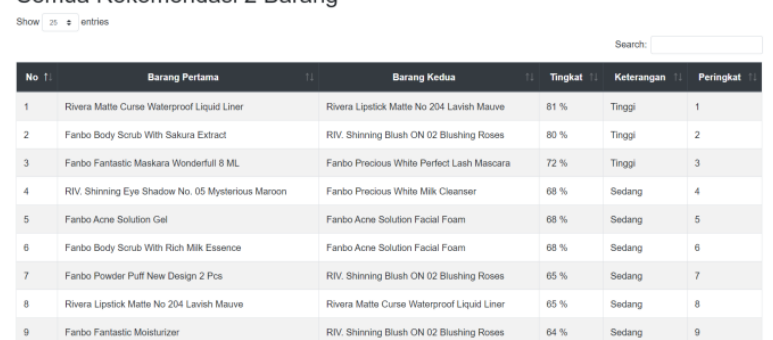

Gambar 3.5 Tampilan Halaman Hasil Rekomendasi Barang

\subsection{Pengujian Black Box}

Pengujian Black Box ini dilakukan untuk menguji keberhasilan jalannya aplikasi pada perancangan ini, seperti tabel berikut ini:

Tabel 3.1 Black Box Testing Penerapan Association Rule Data Mining untuk Rekomendasi Produk Kosmetik menggunakan Algoritma Apriori

\begin{tabular}{|c|l|l|c|c|}
\hline No & $\begin{array}{l}\text { Penguji } \\
\text { an }\end{array}$ & $\begin{array}{l}\text { Hasil Yang } \\
\text { di } \\
\text { Harapkan }\end{array}$ & $\begin{array}{c}\text { Hasil } \\
\text { Penguji } \\
\text { an }\end{array}$ & Ket \\
\hline 1 & $\begin{array}{l}\text { Penguji } \\
\text { an } \\
\text { menu } \\
\text { login } \\
\text { aplikasi }\end{array}$ & $\begin{array}{l}\text { Aplikasi } \\
\text { dapat } \\
\text { melakukan } \\
\text { proses login } \\
\text { dan masuk } \\
\text { ke menu } \\
\text { selanjutnya }\end{array}$ & Sesuai & $\begin{array}{c}\text { Val } \\
\text { id }\end{array}$ \\
\hline 2 & $\begin{array}{l}\text { Penguji } \\
\text { an } \\
\text { menu } \\
\text { data } \\
\text { transaks }\end{array}$ & $\begin{array}{l}\text { Aplikasi } \\
\text { dapat } \\
\text { melakukan } \\
\text { proses } \\
\text { tambah data }\end{array}$ & Sesuai & $\begin{array}{c}\text { Val } \\
\text { id }\end{array}$ \\
\hline
\end{tabular}




\begin{tabular}{|c|c|c|c|c|}
\hline & $\mathrm{i}$ & transaksi & & \\
\hline 3 & $\begin{array}{l}\text { Penguji } \\
\text { an } \\
\text { menu } \\
\text { rekome } \\
\text { ndasi } \\
\text { barang }\end{array}$ & $\begin{array}{l}\text { Aplikasi } \\
\text { dapat } \\
\text { melakukan } \\
\text { proses } \\
\text { rekomendas } \\
\text { i barang } \\
\text { dan } \\
\text { menampilk } \\
\text { an hasil } \\
\text { rekomendas } \\
\text { i barang } \\
\text { menggunak } \\
\text { an } \\
\text { algoritma } \\
\text { Apriori }\end{array}$ & Sesuai & $\begin{array}{c}\text { Val } \\
\text { id }\end{array}$ \\
\hline 4 & $\begin{array}{l}\text { Penguji } \\
\text { an } \\
\text { menu } \\
\text { support } \\
\text { dan } \\
\text { confide } \\
\text { nce }\end{array}$ & $\begin{array}{l}\text { Aplikasi } \\
\text { dapat } \\
\text { mengubah } \\
\text { minimum } \\
\text { support dan } \\
\text { confidence } \\
\text { algoritma } \\
\text { Apriori }\end{array}$ & Sesuai & $\begin{array}{l}\text { Val } \\
\text { id }\end{array}$ \\
\hline 5 & $\begin{array}{l}\text { Penguji } \\
\text { an } \\
\text { menu } \\
\text { daftar } \\
\text { barang }\end{array}$ & $\begin{array}{l}\text { Aplikasi } \\
\text { dapat } \\
\text { melakukan } \\
\text { CRUD } \\
\text { pada menu } \\
\text { daftar } \\
\text { barang }\end{array}$ & Sesuai & $\begin{array}{l}\text { Val } \\
\text { id }\end{array}$ \\
\hline 6 & $\begin{array}{l}\text { Penguji } \\
\text { an } \\
\text { menu } \\
\text { laporan }\end{array}$ & $\begin{array}{l}\text { Aplikasi } \\
\text { dapat } \\
\text { menampilk } \\
\text { an semua } \\
\text { laporan } \\
\text { yang ada } \\
\text { dengan } \\
\text { format PDF }\end{array}$ & Sesuai & $\begin{array}{l}\text { Val } \\
\text { id }\end{array}$ \\
\hline 7 & $\begin{array}{l}\text { Penguji } \\
\text { an } \\
\text { menu }\end{array}$ & $\begin{array}{l}\text { Aplikasi } \\
\text { dapat } \\
\text { membatasi }\end{array}$ & Sesuai & $\begin{array}{l}\text { Val } \\
\text { id }\end{array}$ \\
\hline
\end{tabular}

\begin{tabular}{|c|c|c|c|c|}
\hline & $\begin{array}{l}\text { daftar } \\
\text { putih }\end{array}$ & $\begin{array}{l}\text { user dalam } \\
\text { mengakses } \\
\text { menu-menu } \\
\text { yang } \\
\text { terdapat } \\
\text { pada } \\
\text { aplikasi }\end{array}$ & & \\
\hline 8 & $\begin{array}{l}\text { Penguji } \\
\text { an } \\
\text { menu } \\
\text { jabatan }\end{array}$ & $\begin{array}{l}\text { Aplikasi } \\
\text { dapat } \\
\text { melakukan } \\
\text { CRUD } \\
\text { pada menu } \\
\text { jabatan }\end{array}$ & Sesuai & $\begin{array}{c}\text { Val } \\
\text { id }\end{array}$ \\
\hline 9 & $\begin{array}{l}\text { Penguji } \\
\text { an } \\
\text { menu } \\
\text { akun }\end{array}$ & $\begin{array}{l}\text { Aplikasi } \\
\text { dapat } \\
\text { melakukan } \\
\text { CRUD } \\
\text { pada menu } \\
\text { akun }\end{array}$ & Sesuai & $\begin{array}{c}\text { Val } \\
\text { id }\end{array}$ \\
\hline 10 & $\begin{array}{l}\text { Penguji } \\
\text { an } \\
\text { logout } \\
\text { aplikasi }\end{array}$ & $\begin{array}{l}\text { Aplikasi } \\
\text { dapat } \\
\text { melakukan } \\
\text { proses } \\
\text { logout dan } \\
\text { keluar dari } \\
\text { aplikasi }\end{array}$ & Sesuai & $\begin{array}{c}\text { Val } \\
\text { id }\end{array}$ \\
\hline
\end{tabular}

\section{KESIMPULAN}

Berdasarkan hasil dari menggali data dengan memanfaatkan bidang ilmu menggunakan data mining untuk mencari pola informasi baru, serta analisa mengenai pola pembelian di PT. Fabindo Sejahtera menggunakan aplikasi Rapidminer yang telah disampaikan dalam bab-bab sebelumnya, maka dapat diambil kesimpulan sebagai berikut :

1. Diketahui bahwa penelitian data mining menggunakan algoritma Apriori dapat menghasilkan pola informasi baru yang bermanfaat yang dapat digunakan untuk mengetahui rekomendasi produk kosmetik. 
2. Hasil dari aplikasi Rapidminer mengetahui pola pembelian produk dan implementasi data mining menggunakan algoritma Apriori ini memberikan informasi produk-produk yang di beli sacara bersamaan oleh konsumen yang dapat digunakan oleh PT. Fabindo Sejahtera sebagai strategi pengembangan promosi untuk mendongkrak penjualan produk kosmetik.

3. Association rules ini menghasilkan kombinasi menu dalam pola pembelian oleh konsumen yang dapat digunakan untuk strategi pengembangan promosi yang tepat sasaran. 


\section{DAFTAR PUSTAKA}

[1]. Nofriyansyah, Dicky. 2014. Konsep Data Mining Vs Sistem Pendukung Keputusan.Yogyakarta: Deepublish.

[2]. C, Aprilla Dennis., dkk. 2013. Belajar Data Mining Dengan Rapid Miner. Jakarta.

[3]. Buulolo, Efori. 2020. Data Mining Untuk Perguruan Tinggi. Yogyakarta : Deepublish.

[4]. Santoso Heroe, I Putu Hariyadi. dan Prayitno. 2016, 'Data Mining Analisa Pola Pembelian Produk Dengan Menggunakan Metode Algoritma Apriori', Seminar Nasional Teknologi Informasi dan Multimedia, hh. 19-24.

[5]. Adinugroho, Sigit., dan Yuita Arum Sari. 2018. Implementasi Data Mining Menggunakan Weka. Malang : Universitas Brawijaya Press. 


\section{BIOGRAPHY}

Febriantho, lahir di Tangerang pada 27 Februari 2000. Menyelesaikan kuliah Strata I (S1) pada tahun 2020 pada Program Studi Teknik Informatika di Universitas Buddhi Dharma. Saat ini bekerja sebagai Car Engine Manager di Alin Bengkel Mobil.

\section{Dram Renaldi, S.Kom., M.Kom.}

Tempat tanggal lahir di Tangerang, 11 Januari 1990, adalah lulusan Teknik Informatika (S1) di STMIK PGRI Tangerang pada tahun 2012 dan lulusan Teknologi Sistem Informasi (S2) di Universitas Budi Luhur Jakarta pada tahun 2016 dengan Bidang Keahlian : Desicion Support System dan Multimedia

Edy, berpendidikan formal Strata 1 di Universitas Gunadarma jurusan Teknik Informatika pada tahun 2000 hingga 2004 dan STMIK Eresha jurusan Teknik Informatika dari tahun 2010 hingga 2012. Bekerja sebagai dosen tetap di Fakultas Sains dan Teknologi Universitas Buddhi Dharma dari tahun 2010 hingga sekarang.

Yakub, Saat ini bekerja sebagai dosen Tetap pada Program Studi Teknik Informatika di Universitas Buddhi Dharma. 